DOI: https://doi.org/10.47405/mjssh.v6i10.1126

\begin{tabular}{|c|c|}
\hline 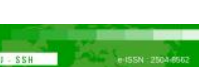 & Malaysian Journal of Social Sciences and Humanities (MJSSH) \\
\hline Malaysian Journal of & Volume 6, Issue 10, October 2021 \\
\hline (MJ-SSH) & e-ISSN : 2504-8562 \\
\hline & $\begin{array}{l}\text { Journal home page: } \\
\text { www.msocialsciences.com }\end{array}$ \\
\hline
\end{tabular}

\title{
Pengalaman Pembelajaran Guru Terhadap Bimbingan SISC+: Manfaatnya Kepada Amalan Pengajaran Guru dan Pencapaian Pelajar
}

\author{
Syamsul Bahri Andi Mapiare', Mohd. Zaki Ishak ${ }^{1}$, Mazlan Mohd Yussof ${ }^{1}$, Syahrul Nizam Salam² \\ ${ }^{1}$ Fakulti Psikologi dan Pendidikan, Universiti Malaysia Sabah (UMS), Sabah, Malaysia \\ 2Pusat Penataran Ilmu dan Bahasa, Kampus Antarabangsa Labuan, Universiti Malaysia Sabah (UMS), Sabah, Malaysia
}

Correspondence: Syahrul Nizam Salam (insantakwa@yahoo.com)

\begin{abstract}
Abstrak
Kementerian Pendidikan Malaysia telah memperkenalkan Pembimbing Pakar Peningkatan Sekolah (SISC+) atau School Improvement Specialist Coach pada tahun 2014 bertujuan memberikan bimbingan langsung kepada guru. Semenjak itu banyak kajian dilakukan terhadap program bimbingan SISC+, namun kajian yang ada masih belum cukup untuk membuktikan bahawa program bimbingan ini memberi manfaat langsung kepada kualiti pengajaran dan pembelajaran (PdP) guru. Sehubungan dengan itu kajian ini diketengahkan dengan tujuan untuk meneroka manfaat program bimbingan SISC+ daripada perspektif guru yang pernah dibimbing. Seramai sepuluh orang guru yang pernah dibimbing oleh SISC+ telah dipilih secara bertujuan untuk ditemu bual menggunakan soalan separa berstruktur. Rakaman temu bual ini kemudian ditranskripsikan baris demi baris, dikod dan dikategorikan untuk memunculkan tema. Tema yang terhasil ini kemudian digunakan untuk menjawab tiga persoalan kajian iaitu cara bagaimana guru menggambarkan pengalaman yang dilalui sewaktu dibimbing oleh pegawai SISC+; cara bagaimana pengalaman sewaktu dibimbing ini memberi manfaat kepada amalan profesional guru; dan cara bagaimana pengalaman pembelajaran ini memberi kesan kepada pencapaian kelas yang diajar. Keputusan kajian mendapati guru menerima baik bimbingan SISC+ sebagai sebahagian daripada peluang pembelajaran yang memberi manfaat langsung kepada amalan profesional mereka, sekali gus memberi kesan kepada pencapaian pelajar bagi kelas yang diajar. Dapatan kajian ini telah membuktikan bahawa program bimbingan SISC+ adalah satu daripada cara untuk meningkatkan amalan pengajaran guru melalui latihan secara in situ di mana manfaatnya bukan sahaja kepada guru malah kepada pelajar. Kesimpulannya, bimbingan SISC+ perlu diperkasa sebagai satu daripada kaedah pembangunan profesional berterusan untuk guru.
\end{abstract}

Kata kunci: program bimbingan guru, pembangunan profesional berterusan, pengalaman pembelajaran, amalan pengajaran guru, pencapaian pelajar

\section{Teachers' Learning Experiences on SISC+ Guidance: Its Benefits To Teachers' Practice and Student Achievement}

\begin{abstract}
Ministry of Education Malaysia has introduced School Improvement Specialist Coach (SISC+) in 2014 aimed at providing direct coaching to the teachers. Although there has been a lot of research on teacher coaching programmes, but research suggests that lack of evidence on coaching program is directly benefits the quality of teaching and learning $(\mathrm{TnL})$ of the teachers. This led the study aimed at exploring the benefits of the SISC+ from the perspective of teachers. A total of ten teachers were
\end{abstract}


purposefully selected. They were interviewed using semi structured questions. The recordings of these interviews were then transcribed line by line, coded and categorized to produce an overarching theme. The resulting theme was then used to answer the three research questions: how do teachers describe their experiences coached by SISC+ officers; how does SISC+ coaching experience benefits teachers' professional practice; and how these learning experiences affect the achievement of the students. The results of the study indicate that teachers receive good SISC+ guidance as part of a learning opportunity that directly benefits their professional practice, and consequently has effect on students' achievement. The SISC+ coaching programme is one of the ways to improve teachers' teaching practices via in situ training in which benefits, not only teachers, but also students. Thus, SISC+ coaching programme needs to be strengthened as part of the continuous professional development for teachers

Keywords: teacher coaching program, continuing professional development, learning experience, teacher practice, student achievement

\section{Pengenalan}

Pada tahun 2012, Kementerian Pendidikan Malaysia (KPM) telah melancarkan Pelan Pembangunan Pendidikan Malaysia 2013-2025 (PPPM 2013-2025). Sebanyak sebelas anjakan telah diperkenalkan dan satu daripadanya berkaitan dengan kajian ini iaitu Anjakan Keenam. Anjakan ini menyatakan bahawa menjelang tahun 2020 semua sekolah tanpa mengira lokasi, jenis dan saiz akan menyediakan pendidikan yang baik dan holistik kepada murid dengan harapan tidak ada lagi sekolah berprestasi rendah di seluruh negara (Kementerian Pelajaran Malaysia, 2013). Ini kerana dalam kajian Syahrul et al. (2018), menunjukkan pencapaian atau prestasi rendah menunjukkan tahap pembangunan konsep kendiri yang perlu diberi perhatian dalam pendidikan. Konsep kendiri yang baik dapat meningkatkan pencapaian guru-guru sekolah melalui bimbingan SISC+.

Bagi mempercepatkan proses penambahbaikan prestasi sekolah, maka pada tahun 2014 sokongan kepada guru diperhebat melalui peluasan peranan Pembimbing Pakar Peningkatan Sekolah (School Improvement Specialist Coach, SISC+) atau pembimbing guru. Mereka (SISC+) bekerja rapat dengan guru menyokong pelaksanaan kurikulum dan pentaksiran baharu, membimbing dan melatih guru dalam kemahiran pedagogi melalui latihan langsung kepada guru secara in situ (Kementerian Pelajaran Malaysia, 2013). Sokongan terhadap guru-guru ini dapat meningkatkan lagi kualiti perkhidmatan yang diberikan.

Semenjak peluasan peranan ini, banyak kajian telah dilakukan terhadap program bimbingan SISC+ (Zubaidah et al., 2019). Limpahan kajian ini didorong oleh kepercayaan bahawa bimbingan SISC+ berupaya meningkatkan kualiti pengajaran guru dan pencapaian pelajar (Denton \& Hasbrouck, 2009; Desimone, 2009; Knight, 2009; Marzano, Waters, \& McNulty, 2016; Darling-Hammond, Hyler, \& Gardner, 2017; Zubaidah Bibi et al., 2019; Desimone \& Pak, 2017). Ini membuktikan program bimbingan SISC+ telah banyak membawa perubahan peningkatan kualiti dalam dunia pendidikan negara.

\section{Pernyataan Masalah}

Usaha KPM memperkenalkan SISC+ bagi menyokong perkembangan profesional langsung kepada guru nampaknya telah berjaya mencapai sasaran apabila semakin diterima baik oleh guru (Noel \& Zamri, 2017; Wong \& Nur Ain, 2018; Sarabiah, 2018). Begitu juga bimbingan yang dilaksanakan oleh SISC+ berkesan dalam meningkatkan kualiti pengajaran guru (Sarabiah \& Zamri, 2019; Rozita Radhiah et al., 2016; Nur Syamsila \& Siti Mistima, 2017; Sarabiah, 2018; Lonsiong \& Dg Norizah, 2019; Zubaidah Bibi et al., 2019; Wan Fadhrurrahman et al., 2020). Hal ini bertepatan dengan laporan yang dikeluarkan oleh Unit Pelaksanaan dan Prestasi Pendidikan (PADU), bahawa $98.74 \%$ kualiti 
pengajaran dan pembelajaran (PdP) guru dibimbing oleh SISC+ mencapai tahap baik minima SKPMg2 Standard 4 (PADU, 2019).

Sungguhpun bimbingan SISC+ diterima baik dan berkesan dalam meningkatkan kualiti pengajaran guru, namun kajian yang ada masih belum cukup untuk membuktikan bahawa program bimbingan ini berjaya mengubah amalan pengajaran guru (Zubaidah et al., 2019) dan juga pencapaian pelajar (Davrajoo \& Letchumanan, 2019). Kerana menurut Rozita et al. (2016) untuk mengubahnya memerlukan masa yang panjang dan konsisten.

Sehubungan dengan itu, literatur kajian lepas mencadangkan agar lebih banyak penelitian terperinci dilakukan terhadap program bimbingan SISC+ (Rozita et al., 2016; Mohd Hilmi \& Jamil, 2017; Wong \& Nur Ain Elzira, 2018; Sarabiah, 2018; Zubaidah et al., 2019) terutamanya yang menumpu kepada pengamalan pembelajaran sebenar guru yang terbabit secara langsung dengan aktiviti bimbingan SISC+ (Teemant, 2014; Sarabiah, 2018; Zubaidah et al., 2019).

Hal ini menjadi mustahak kerana setelah banyak usaha dicurahkan, tidak banyak diketahui bagaimana guru memberi makna terhadap pengalaman pembelajaran yang dilalui sewaktu dibimbing oleh SISC+, bagaimana pengalaman pembelajaran ini berjaya mengubah amalan pengajaran guru dan bagaimana pengalaman pembelajaran ini meningkatkan pencapaian pelajar bagi kelas yang diajar.

\section{Tujuan dan Persoalan Kajian}

Selaras dengan pernyataan masalah di atas, maka kajian ini dijalankan dengan tujuan untuk meneroka pengalaman pembelajaran guru yang pernah dibimbing oleh SISC+. Melalui temu bual bersemuka dengan menanyakan soalan berbentuk separa berstruktur, pengkaji berusaha memahami bagaimana makna-makna dibina dalam setiap peristiwa yang dilalui sewaktu dibimbing oleh SISC+. Maknamakna ini kemudian dianalisis untuk memunculkan tema bagi menjawab tiga persoalan kajian, iaitu; (a) cara bagaimana guru menggambarkan pengalaman yang dilalui sewaktu bekerja bersama dengan SISC+; (b) cara bagaimana pengalaman pembelajaran sewaktu dibimbing ini memberi manfaat kepada amalan pengajaran guru; dan (c) cara bagaimana pengalaman pembelajaran ini memberi kesan kepada pencapaian kelas yang diajar.

\section{Metod Kajian}

Dalam kajian ini, metodologi kajian dalam aspek mengenal pasti populasi telah membincangkan secara rasional tentang pemilihan sampel kajian yang terlibat dalam memberikan data dan maklumat yang di kumpul untuk menjawab soalan atau objektif kajian (Gazali \& Sufean, 2016).

\section{Reka Bentuk Kajian}

Memandangkan pengkaji dalam kajian ini berusaha meneroka pengalaman pembelajaran sebenar guru sewaktu bekerja bersama dengan SISC+, maka pendekatan kualitatif menggunakan reka bentuk kajian kes adalah paling sesuai. Hal ini kerana, pendekatan kualitatif berupaya meneroka sesuatu pengalaman tersirat yang dialami oleh seseorang (guru) dalam suasana, tempat dan latar sebenar (sekolah) (Patton, 2002; Yin, 2016). Justeru, apabila pengalaman seseorang dijadikan kajian, maka menurut Yin (2016) dan Creswell (2013) pendekatan kualitatif adalah yang paling sesuai. Pengalaman yang dilalui oleh guru ini sangat bernilai dan tidak boleh diulangi dengan cara lakonan semula (Creswell, 1994).

Manakala, kajian kes dipilih sebagai reka bentuk kajian memandangkan keupayaannya mengkaji sesuatu entiti atau fenomena (sama ada berupa satu program, peristiwa, proses, institusi atau kelompok sosial dalam satu tempoh masa (Heigham \& Croker, 2009; Othman, 2017; Polit \& Beck, 2012) menggunakan pelbagai metod pengumpulan data (Yin, 2016). Justeru, apabila pengalaman guru sewaktu mengikuti program bimbingan SISC+ dijadikan kajian maka, menurut Stake (2010) kajian kes adalah paling sesuai 


\section{Lokasi Kajian}

Bagi menyempurnakan kajian ini, maka pengkaji telah memilih secara bertujuan sepuluh buah sekolah dalam daerah Sandakan sebagai lokasi kajian. Sekolah-sekolah ini dipilih berdasarkan kriteria seperti berikut: pertama, sekolah-sekolah ini telah menunjukkan peningkatan ketara dalam Ujian Penilaian Sekolah Rendah (UPSR) bagi tiga tahun berturut-turut (2017-2019); kedua, semua sekolah-sekolah ini kerap dibimbing oleh SISC+ sepanjang tiga tahun berturut-turut (2017-2019). Tempoh bimbingan yang lama ini sudah pasti banyak peristiwa yang berlangsung antara guru dengan SISC + . Peristiwa berupa pengalaman pembelajaran sewaktu dibimbing ini menurut Seidman (2006) amat bernilai untuk dipelajari dan diteladani; dan ketiga, hanya sekolah-sekolah yang melepasi purata skor SKPMg2 Standard 4 melebihi tahap minimum sahaja dipilih. Penetapan ini adalah berdasarkan dapatan PADU pada tahun 2018 yang mendapati guru-guru yang dibimbing oleh SISC+ secara puratanya memperoleh skor $98.74 \%$ (PADU, 2019).

\section{Peserta Kajian}

Daripada sepuluh buah sekolah, pengkaji telah berjaya merekrut sepuluh orang guru (lima lelaki dan lima perempuan) untuk menyertai kajian ini. Mereka terdiri daripada guru-guru yang berpotensi untuk dipelajari secara meluas (Patton, 2002), rela hati menjadi sebahagian daripada kajian (Liamputtong, 2007), berwibawa (Yin, 2016; Glense, 2011) dan bersetuju menggambarkan pengalaman sebenar mereka tanpa ada sebarang unsur paksaan dan ancaman (Patton, 2002; Yates et al., 2012).

\section{Kaedah Pengumpulan Data}

Untuk meneroka pengalaman pembelajaran para peserta kajian, maka kesemua mereka ditemu bual menggunakan soalan separa berstruktur. Rasional pengkaji memilih kaedah ini adalah kerana kajian ini tujuannya adalah untuk meneroka pengalaman pembelajaran mereka sewaktu dibimbing oleh SISC+. Apabila pengalaman dijadikan kajian, maka menurut Remenyi et. al., (2003) dan Sediman (2006) temu bual adalah kaedah paling sesuai untuk mengumpul data. Tambah Seidman (2006) lagi, pengetahuan yang diperoleh daripada pengalaman yang diceritakan melalui pesanan lisan ini amat bernilai untuk dipelajari dan diteladani.

\section{Prosedur Kutipan Data}

Bagi memastikan kajian ini diyakini penemuannya, maka pengkaji terlebih mendapatkan kebenaran melaksanakan kajian daripada EPRD, JPN dan PPD. Tanpa kebenaran daripada stakeholder menurut Neuman (2007), Creswell dan Creswell (2018) sesuatu kajian itu tidak beretika.

Apabila kebenaran diperoleh daripada EPRD, JPN dan PPD, maka pengkaji pun melaksanakan beberapa siri temu bual rintis sebagaimana dicadangkan oleh Castillo-Montoya (2016). Hasil daripada rintis ini, maka terhasillah protokol kajian merangkumi prosedur memasuki lokasi kajian, prosedur membina hubungan dan memulakan temu bual, prosedur mengumpul data dan prosedur keluar dari lokasi kajian berserta dengan soalan temu bual. Soalan-soalan temu bual ini pula telah dimurnikan oleh pakar yang dilantik dan berwibawa.

Setelah segala persiapan telah dirapikan, maka pengkaji pun menghubungi pihak sekolah bagi memaklumkan mereka bahawa pengkaji sedang melaksanakan kajiannya di situ sambil mengemukakan surat-surat kebenaran daripada EPRD, JPN dan PPD. Sebaik sahaja mendapatkan persetujuan daripada pihak sekolah, maka langkah selanjutnya adalah menghubungi para peserta kajian untuk menetapkan jadual pertemuan mengikut kesesuaian masa. Hal ini penting memandangkan seseorang pengkaji itu tidak boleh mengganggu tugas mereka sebagai guru dan hanya menemui peserta kajian apabila mereka benar-benar bersedia untuk ditemu bual (Kvale, 1996).

Pada tarikh yang telah ditetapkan, pengkaji pun menemu bual peserta kajian berpandukan protokol temu bual. Di sepanjang sesi temu bual, pengkaji juga turut membuat nota lapangan untuk mencatatkan peristiwa-peristiwa penting yang berlaku. Nota lapangan menurut Bogdan dan Biklen (2007) penting 
bagi membantu pengkaji mengingati semula peristiwa semasa membuat transkripsi nanti. Tidak lupa juga pengkaji turut mengutip dokumen berkaitan dengan bimbingan SISC+ yang mungkin masih dalam simpanan oleh peserta kajian.

Setelah selesai temu bual, pengkaji memaklumkan bahawa akan datang semula untuk mendapatkan maklumat tambahan sekiranya perlu dan meminta mereka mengesahkan transkrip temu bual. Tujuannya bagi memastikan bahawa teks dalam transkrip sama seperti apa yang diceritakan oleh para peserta kajian. Pada kesempatan yang lain, pengkaji menemu bual pula Guru Besar dengan tujuan untuk mendapatkan pandangan mereka terhadap bimbingan SISC+ dari sudut padang mereka. Begitu juga dengan sesi temu bual kumpulan fokus pula dilaksanakan sebaik sahaja semua peserta kajian selesai di temu bual. Temu bual Guru Besar dan kumpulan fokus digunakan untuk tujuan triangulasi.

Kesemua peristiwa sebelum, semasa dan selepas kajian ini dirakam dalam jurnal kajian pengkaji sebagai satu daripada cara pengkaji meningkatkan kualiti kajian ini sebagaimana dicadangkan oleh Auerbach dan Silverstein (2003) sebagai bukti meyakinkan bahawa kajian benar-benar dilaksanakan.

\section{Prosedur Analisis Data}

Proses menganalisis data ini dilakukan sejurus sahaja selesai satu-satu temu bual tanpa dilengahkan (Corbin \& Strauss, 2008). Hal ini bagi menjamin ingatan pengkaji sewaktu temu bual masih segar dalam ingatan (Creswell, 2012). Sehubungan dengan itu, berikut adalah langkah yang diambil oleh pengkaji sejurus sahaja selesai menemu bual peserta kajian.

Semua rakaman temu bual ditranskripsikan ungkapan demi ungkapan. Semasa proses itu berlangsung, pengkaji mencatatkan nota-nota penting yang mungkin berguna pada peringkat seterusnya. Transkripsi yang telah lengkap ini kemudian disemak silang dengan nota lapangan. Langkah ini dilakukan secara menyeluruh tanpa meninggalkan apa juga yang didengar dan diperhatikan. Sebagai tambahan, pengkaji memadamkan semua nama individu yang diceritakan oleh peserta kajian dan menggantikannya dengan nama samaran termasuklah nama peserta kajian, sekolah, daerah, kelas dan jalan dalam semua transkrip sebagaimana disyorkan oleh Seidman (2006) bagi mengelakkan para peserta kajian terdedah kepada risiko kemudaratan.

Bagi meningkatkan kredibiliti kajian, maka pengkaji memulangkan semula transkrip kepada peserta kajian untuk disemak, ditambah, dikurangkan atau dibetulkan sebelum disahkan. Langkah ini menurut Creswell (2009) perlu bagi mengekalkan hubungan dan kepercayaan peserta kajian serta mengurangkan bias pengkaji.

Setelah itu semua transkrip dan dokumen yang dikutip diindeks. Semua data ini disimpan dalam satu folder utama dalam komputer pengkaji yang diberikan penyulitan bagi melindungi daripada dicerobohi oleh orang yang tidak bertanggungjawab. Sebagai langkah berjaga-jaga semua data ini disalin dan disimpan dalam One Drive Cloud pengkaji secara atas talian.

\section{Pengekodan}

Proses pengekodan melibatkan enam langkah sebagaimana dicadangkan oleh Auerbach dan Silverstein (2003) iaitu:

i. Berpandukan kepada persoalan kajian, pengkaji membaca transkrip berulang-ulang kali bagi membiasakan diri dengan data.

ii. Kemudian, pengkaji menandai teks atau frasa kata yang berkaitan dengan persoalan kajian untuk dianalisis lebih lanjut. Memo ditulis bagi mencatatkan sebab mengapa pengkaji memilih teks atau frasa kata tersebut sebagai berkaitan dengan persoalan kajian. Langkah (a) dan (b) diulang untuk kesemua transkrip yang ada dalam simpanan pengkaji. 
iii. Seterusnya, kesemua teks atau frasa kata yang berkaitan ini kemudian dikeluarkan daripada transkrip asal dan disimpan dalam satu dokumen yang lain. Teks atau frasa kata ini kemudian dikelompokkan berdasarkan idea berulang.

iv. Idea-idea berulang ini kemudian dikelompokkan untuk membentuk tema.

v. Tema-tema kemudian dikumpulkan membentuk konstruk teroretikal yang lebih abstrak selaras dengan kerangka teori kajian.

vi. Bina naratif teori dengan menceritakan semula kisah peserta kajian dari segi konstruk teori.

\section{Hasil Kajian}

Sebanyak 155 teks berkaitan berjaya dikeluarkan daripada kesemua transkrip asal. Teks-teks berkaitan ini kemudian dikelompokkan membentuk 34 idea berulang. Idea-idea berulang ini kemudian dikategorikan membentuk enam tema iaitu aspek yang digemari guru, aspek yang kurang digemari guru, meningkatkan pengetahuan, meningkatkan amalan pengajaran, memotivasikan guru dan pencapaian pelajar. Tema-tema ini kemudian disusun membentuk konstruk teoretikal yang kemudian dipersembahkan dalam bentuk naratif teori sebagai dapatan kajian.

1. Pengalaman guru

A. Aspek yang digemari guru

RI\#01 Guru menghargai bantuan SISC+ dan mengalu-alukan kedatangan mereka

RI\#02 Guru menganggap SISC+ sebagai rakan yang suka menolong dan membantu

mereka

RI\#03 Guru tiada kekangan/masalah bekerja dengan SISC+

RI\#04 Guru menyatakan program bimbingan SISC+ sangat bagus, amat baik dan perlu

diteruskan

RI\#05 SISC+ penghubung antara atasan dengan sekolah

RI\#06 SISC+ mengambil berat masalah guru

RI\#07 SISC+ sebagai sumber rujukan sebab banyak idea dan ilmunya

RI\#08 Guru suka SISC+ mudah dihubungi

RI\#09 Guru suka maklum balas pantas daripada SISC+

RI\#10 Guru suka apabila SISC+ menunjuk cara / menunjuk ajar

RI\#11 Guru suka SISC+ mengajar bersama

RI\#12 SISC+ melibatkan guru dalam merancang pembelajaran

RI\#13 Guru suka SISC+ kongsi modul/bahan pengajaran dan amalan terbaik

RI\#14 Pencerapan SISC+ tidak bersifat penilaian

RI\#15 Guru suka SISC+ yang tidak menekan

RI\#16 Guru dan SISC+ sama-sama meningkatkan ilmu

RI\#17 SISC+ melibatkan hubungan timbal balik

RI\#18 Aspek bimbingan SISC+ merangkumi pedagogi

RI\#19 Bimbingan SISC+ bermanfaat dan bermakna

B. Aspek yang kurang digemari guru

RI\#20 Guru jika tidak dipantau lain cara mengajarnya, melakukan amalan biasa

RI\#21 SISC+ buat guru kalang kabut dan tidak selesa

RI\#22 Guru tidak suka dicerap

RI\#23 Guru tidak suka dikomen

2. Manfaat bimbingan SISC+

C. Meningkatkan pengetahuan

RI\#24 Meningkatkan pengetahuan guru

D. Meningkatkan amalan pengajaran

RI\#25 SISC+ mewujudkan ruang perkongsian idea dan pengalaman baharu

RI\#26 Memberi impak kepada amalan pengajaran guru

RI\#27 Aspek bimbingan SISC+ merangkumi pentaksiran

RI\#28 Aspek bimbingan SISC+ merangkumi pengurusan panitia

RI\#29 SISC+ memantapkan amalan pengajaran guru 
E. Memotivasikan guru

RI\#30 Kesan bimbingan SISC+ - motivasi

RI\#31 SISC+ meningkatkan iltizam guru, keyakinan dan tanpa putus asa

3. Kesan bimbingan SISC+ terhadap pelajar

F. Pencapaian pelajar

RI\#32 Meningkatkan keputusan

RI\#33 Meningkatkan pencapaian

RI\#34 Impak kepada murid

\section{Persoalan Kajian 1: Cara bagaimana guru menggambarkan pengalaman yang dilalui sewaktu bekerja bersama dengan SISC+.}

Berdasarkan pengalaman yang diceritakan oleh para peserta kajian, dua tema utama muncul bagi menggambarkan pengalaman pembelajaran guru iaitu aspek yang digemari guru dan tidak digemari guru. Guru menyatakan bahawa tidak ada masalah atau kekangan bekerja sama dengan SISC+ malah mengalu-alukan kedatangan mereka. Bagi mereka, SISC+ adalah rakan yang suka menolong dan membantu mereka, mengambil berat akan masalah mereka dan sumber rujukan. Sebagai rakan, SISC+ mudah dihubungi, memberi maklum balas pantas dan penghubung antara pihak atasan dengan sekolah.

Semasa proses bimbingan, guru suka apabila SISC+ melibatkan mereka dalam proses merancang, melaksanakan pengajaran bersama atau menunjuk cara bagaimana sesuatu amalan baharu dilaksanakan kemudian mereflek semula pengajaran dalam suasana yang tidak menekan. Begitu juga guru menyukai apabila SISC+ berkongsi modul dan bahan pengajaran serta amalan pengajaran daripada sekolah lain.

Walau bagaimanapun segelintir peserta kajian tidak selesa apabila dicerap dalam bilik darjah dan dikomen pengajarannya terutama guru berpengalaman. Mereka berpandangan tidak ada guru yang suka dicerap. Walaupun mereka tahu pencerapan SISC+ bukan berbentuk penilaian namun perasaan resah, gelisah dan tidak selesa tetap ada. Berlainan pula dengan guru baharu, mereka menyukai pencerapan kerana bagi mereka inilah peluang untuk perkongsian ilmu.

Sungguhpun begitu guru menyatakan bahawa program bimbingan SISC+ sangat bagus, amat baik dan perlu diteruskan. Bagi mereka inilah peluang untuk sama-sama meningkatkan ilmu secara timbal balik agar kedua-dua pihak mendapat manfaat dan pengalaman bermakna.

\section{Persoalan Kajian 2: Cara bagaimana pengalaman pembelajaran sewaktu dibimbing ini memberi manfaat kepada amalan pengajaran guru}

Berdasarkan pengalaman pembelajaran para peserta kajian, banyak pengalaman dan manfaat diperoleh daripada program bimbingan SISC+ berkaitan dengan amalan pengajaran. Bimbingan dan sokongan yang diberikan oleh SISC+ meningkatkan pengetahuan dan mengemas kini amalan pengajaran guru merangkumi pengurusan panitia. Aktiviti paling bermakna adalah apabila guru dilibatkan sama dalam merancang pengajaran menggunakan pelbagai strategi, kaedah dan teknik. Kemudian sama-sama melaksanakan pengajaran sambil mencerap antara satu sama lain. Hasil pencerapan ini kemudian direflek semula untuk mengenal pasti kekuatan dan kelemahan pengajaran untuk tujuan penambahbaikan mutu pengajaran. Aktiviti sebegini menurut guru memberikan mereka pengalaman dan idea baharu berbanding dengan hanya mencadangkan penambahbaikan selepas pencerapan. Melalui aktiviti ini kedua-dua pihak mendapat manfaat dan secara tidak langsung meningkatkan motivasi, iltizam dan keyakinan agar tidak mudah putus asa.

\section{Persoalan Kajian 3: Cara bagaimana pengalaman pembelajaran ini memberi kesan kepada pencapaian kelas yang diajar}

Menyentuh persoalan kajian ini, pada pandangan guru, kesan bimbingan SISC+ terhadap pencapaian pelajar tidak berlaku serta-merta dan memerlukan masa. Namun aktiviti PdP yang dirancang dengan baik pada pandangan guru mampu menarik minat murid untuk belajar. Murid dilihat seronok belajar 
dan mencuba apa saja yang diminta oleh guru. Pengalaman pembelajaran yang dilalui ini melekat di minda dan digunakan pula di rumah untuk tujuan ulang kaji.

\section{Kesimpulan}

Secara keseluruhan, pengalaman yang dilalui guru sewaktu bekerja sama dengan SISC+ pelbagai rupa. Ada yang terus serasi dan ada pula yang tidak. Situasi sebegini menurut Jacobs et al. (2017) sudah menjadi perkara biasa apabila sesuatu pembaharuan diperkenalkan dalam bidang pendidikan, Hal ini juga ada kaitannya dengan sikap defensif guru yang cuba mengekalkan amalan biasa kerana sudah berada dalam zon selesa (Zubaidah, Yamat, \& Wahiza, 2020). Walau bagaimanapun bagi guru baharu mereka memanfaatkan pengalaman ini untuk meningkatkan pengetahuan kandungan pedagogi mereka.

Begitu juga dapatan kajian menunjukkan bahawa pengalaman pembelajaran yang dilalui oleh guru memberi manfaat kepada amalan pengajaran mereka sekiranya mereka dilibatkan sama secara aktif (menentukan aspek pembelajaran, merancang pembelajaran, melaksanakan aktiviti pengajaran dan pembelajaran secara bimbingan rakan sebaya dan kemudian mereflek semula amalan pengajaran), latihan dan bimbingan berkait rapat dengan isu yang sedang dihadapi guru dan dilaksanakan secara berterusan. Hal ini menunjukkan bahawa program bimbingan SISC+ memiliki ciri-ciri pembangunan profesional efektif sebagaimana dinyatakan oleh Desimone dan Pak (2017) iaitu hendaklah berkaitan dengan kandungan yang diajar oleh guru, melibatkan penyertaan aktif, koheren dengan bidang tugas guru, berdasarkan keperluan dan dilaksanakan secara berterusan.

Manakala kesan bimbingan SISC+ terhadap pencapaian pelajar adalah tidak secara langsung. Hal ini sepadan dengan dapatan Davrajoo dan Letchumanan (2019) yang hanya menunjukkan sedikit perubahan. Sungguhpun demikian guru menyedari bahawa pengalaman pembelajaran yang dilalui sewaktu bekerja bersama dengan SISC+ membuatkan guru dekat dengan murid, memahami masalah mereka dan keperluan pembelajaran mereka.

Kesimpulannya, data yang dikumpulkan daripada kajian ini dapat memberi maklumat tambahan kepada penyelidikan semasa bagi membuktikan bagaimana kerjasama antara guru dan pegawai SISC+ berjaya menghasilkan pengalaman pembelajaran yang berkesan. Kemudian daripadanya juga guru dapat memperkemas dan menyesuaikan amalan pengajaran baharu dengan amalan pengajaran sedia ada sekali gus meningkatkan pencapaian pelajar. Walau bagaimanapun beberapa perkara perlu dipertimbangkan sewaktu merancang pembelajaran mereka, kerana guru sebagai pelajar dewasa kecenderungan belajarnya adalah termotivasi oleh keadaan, minat mereka untuk belajar, keinginan untuk memajukan diri, dan peranan sosial mereka dalam organisasi di mana dia berada (Merriam \& Bierema, 2013). Begitu juga lima ciri pembangunan profesional efektif perlu dipertimbangkan sebagaimana dijelaskan sebelum ini.

Dapatan kajian ini telah membuktikan bahawa program bimbingan SISC+ adalah satu daripada cara untuk meningkatkan amalan pengajaran guru melalui latihan secara in situ di mana manfaatnya bukan sahaja kepada guru malah kepada pelajar. Justeru bimbingan SISC+ perlu diperkasa sebagai satu daripada kaedah pembangunan profesional berterusan langsung kepada guru. Namun demikian kajian lebih lanjut perlu dilakukan berupa kajian lapangan untuk suatu tempoh masa yang panjang untuk meneliti proses bimbingan yang berlangsung antara guru dengan pegawai SISC+.

\section{Rujukan}

Auerbach, C. F., \& Silverstein, L. B. (2003). Qualitative Data. New York: New York University Press.

Bogdan, R. C., \& Biklen, S. K. (2007). Qualitative research for education: An introduction to theory and methods. https://doi.org/10.1177/1468794107085301

Castillo-Montoya, M. (2016). Preparing for interview research: The interview protocol refinement framework. Qualitative Report, 21(5), 811-831. 
Corbin, J., \& Strauss, A. (2008). Qualitative Research. New York: SAGE Publications, Inc.

Creswell, J. W. (1994). Research Design: Qualitative \& Quantitative Approach. SAGE Publications, Inc.

Creswell, J. W. (2009). Research design: Qualitative, quantitative, and mixed methods approaches.

Creswell, J. W. (2012). Educational research: Planning, conducting, and evaluating quantitative and qualitative research. Educational Research, 4. https://doi.org/10.1017/CBO9781107415324.004

Creswell, J. W. (2013). Qualitative, quantitative, and mixed methods approaches. Research Design, 126. https://doi.org/10.2307/3152153

Darling-Hammond, L., Hyler, M. E., \& Gardner, M. (2017). Effective Teacher Professional Development, (June). Retrieved from https://learningpolicyinstitute.org/sites/default/files/productfiles/Effective_Teacher_Professional_Development_REPORT.pdf

Davrajoo, E., \& Letchumanan, M. (2019). School improvement specialist coach plus (SISC+) programme: Impact on teachers' pedagogical skills and students' performance in mathematics classroom. ASM Science Journal, 12(1), 137-149.

Denton, C. A., \& Hasbrouck, J. (2009). A Description of Instructional Coaching and its Relationship to Consultation. Journal of Educational and Psychological Consultation, 19(2), 150-175. https://doi.org/10.1080/10474410802463296

Desimone, L. M. (2009). Improving Impact Studies of Teachers' Professional Development: Toward Better Conceptualizations and Measures. Educational Researcher, 38(3), 181-199. https://doi.org/10.3102/0013189X08331140

Desimone, L. M., \& Pak, K. (2017). Instructional Coaching as High-Quality Professional $\begin{array}{llll}\text { Development. Theory } & \text { Into } & \text { Practice, } & 56(1),\end{array}$ https://doi.org/10.1080/00405841.2016.1241947

Gazali dan Sufean (2016). Metodologi penyelidikan dalam pendidikan: Amalan dan analisis kajian. Penerbit Universiti Malaya, Kuala Lumpur

Glense, C. (2011). Becoming Qualitative Researchers: An Introduction. Boston: Pearson.

Heigham, J., \& Croker, R. A. (Eds.). (2009). Qualitative Research in Applied Linguistics. Palgrave Macmillan.

Jacobs, J., Boardman, A., Potvin, A., \& Wang, C. (2017). Understanding Teacher Resistance to Instructional Coaching. Professional Development in Education, 5257(November), 1-14. https://doi.org/10.1080/19415257.2017.1388270

Kementerian Pelajaran Malaysia. (2013). Malaysia Education Blueprint 2013 - 2025. Education, 27(1), 1-268. https://doi.org/10.1016/j.tate.2010.08.007

Knight, J. (2009). Coaching: The key to Translating Research Into Practice Lies in Continuous, Jobembedded Learning With Ongoing Support. Journal of Staff Development, 30(1), 18-22.

Kvale, S. (1996). An Introduction to Qulaitative Research Interveiwing. California: SAGE Publications, Inc. https://doi.org/10.1093/iclqaj/10.3.653

Liamputtong, P. (2007). Researching the Vulnerable. London: SAGE Publications, Inc. https://doi.org/10.4135/9781849209861

Lonsiong, D. U., \& Dg Norizah, A. K. @ D. (2019). Interaksi Kepimpinan Perkongsian Mentor Melalui Motivasi Kerja Guru. Malaysian Journal of Social Sciences and Humanities, 4(7), 68-76.

Marzano, R. J., Waters, T., \& McNulty, B. A. (2016). Raising Student Achievement Through Professional Development. Journal of Elementary Science Education, 1(1), 1-12.

Merriam, S. B., \& Bierema, L. L. (2013). Adult learning: Linking Theory and Practice. John Wiley \& Son.

Mohd Hilmi, A., \& Jamil, A. (2017). Persepsi Guru Terhadap Program Pembimbing Pakar Peningkatan Sekolah (SISC+). Seminar on Transdisciplinary Education (STEd2017), 198-205. Retrieved from https://sted2017.files.wordpress.com/2016/12/1-24-mohd-hilmi-anwa-jamilahmad.pdf

Neuman, L. W. (2007). Basic of Social Research Qualitative and Quantitative Approaches (2nd ed.). Boston: Pearson International Edition.

Noel Jimbai, A. B., \& Zamri, M. (2017). Penerimaan guru-guru bahasa melayu terhadap bimbingan dan pementoran jurulatih sisc+. Jurnal Pengurusan Dan Kepimpinan Pendidikan.

Nur Syamsila, M. H., \& Siti Mistima, M. (2017). Guided Teachers' Perception on The Impact of The Mathematics' School Improvement Specialist Coach. Seminar Pendidikan Serantau Ke-8, (2012), 724-728. Retrieved from https://seminarserantau2017.wordpress.com 
Othman, L. (2017). Penyelidikan Kualitatif: Pengenalan Kepada Teori dan Metode (2nd ed.). Perak: Penerbit Universiti Pendidikan Sultan Idris.

PADU. (2019). Laporan Tahunan 2018 Pelan Pembangunan Pendidikan Malaysia 2013-2025.

Patton, M. Q. (2002). Qualitative Research and Evaluation Methods. Qualitative Inquiry (Third). Los Angeles: SAGE Publications, Inc. Retrieved from http://books.google.com/books/about/Qualitative_research_and_evaluation_meth.html?id=FjBw2 oi8El4C

Polit, D. F., \& Beck, C. T. (2012). Nursing Research: Generating and Assessing Evidance for Nursing Practice (9th ed.). Philadelphia, PA: Lippincott Williams and Wilkins. https://doi.org/10.1017/CBO9781107415324.004

Remenyi, D., Williams, B., Money, A., \& Swarts, E. (2003). Doing Research in Business and Management: An Introduction to Process and Methods. London: SAGE Publications, Inc.

Rozita Radhiah, S., Mohammad, B., \& Azhar, M. S. (2016). Bimbingan dan Pementoran Berfokus oleh SISC+ BM: Impak Terhadap Kualiti Pengajaran Guru Bahasa Melayu di Sekolah-Sekolah Menengah Daerah Samarahan, Sarawak. Jurnal Pendidikan Malaysia, 41(2), 131-139.

Sarabiah, J. (2018). Persepsi, Amalan Dan Keberkesanan Bimbingan Jurulatih SISC+ dari Perspektif Guru Bahasa Melayu. Jurnal Pendidikan Bahasa Melayu - JPBM (Malay Language Education Journal - MyLEJ), 8(1), 42-52.

Sarabiah, J., \& Zamri, M. (2019). Amalan dan keberkesanan bimbingan jurulatih sisc+ dari perspektif guru bahasa melayu. Jurnal Pengurusan Dan Kepimpinan Pendidikan.

Sediman, I. (2006). Review of Interviewing as Qualitative Research: A Guide for Researchers in Education and the Social Sciences. Contemporary Psychology: A Journal of Reviews (3rd ed., Vol. 37). New York: Teachers College Press. https://doi.org/10.1037/032390

Stake, R. E. (2010). Qualitative Research: Studying How Things Work. The Guilford Press. New York: The Guilford Press. https://doi.org/10.1017/CBO9781107415324.004

Syahrul Nizam Salam, Abdul Said Ambotang, Ghazali Hassan Sulaiman. (2018). Pengaruh Faktor Penyumbang Terhadap Kendiri Pelajar Ekonomi Tingkatan Enam Di Sabah. Jurnal Penyelidikan Akademik, Institut Pendidikan Guru Malaysia, Kementerian Pendidikan Malaysia, 3(34), 40-57

Syahrul Nizam Salam, Abdul Said Ambotang, Ghazali Hassan Sulaiman. (2019). Hubungan Sikap Terhadap Ekonomi Dan Kefahaman Konsep Ekonomi Dengan Kendiri Pelajar Ekonomi. Jurnal Kurikulum, Bahagian Pembangunan Kurikulum, Kementerian Pendidikan Malaysia, 4(34), 16-29

Teemant, A. (2014). A mixed-methods investigation of instructional coaching for teachers of diverse learners. Urban Education, 49(5), 574-604. https://doi.org/10.1177/0042085913481362

Wan Fadhrurrahman, W. M. R., Al Amin, M., \& Aziah, I. (2020). Professional Learning Community: Strategi Bimbingan Instruksional dan Alaman Profesional Guru. Jurnal Kepimpinan Pendidikan, 7(3), 38-54.

Wong, S. H., \& Nur Ain Elzira, A. (2018). Bimbingan dan Pementoran Pembimbing Pakar Peningkatan Sekolah (SISC+) Menurut Perpspektif Guru Dibimbing (GDB). International Journal of Education, Psychology and Counselin, 3(13), 57-72.

Yates, C., Partridge, H., \& Bruce, C. (2012). Exploring information experiences through phenomenography. Library and Information Research Volume, 36(112), 96-119.

Yin, R. K. (2016). Qualitative Research From Start to Finish (2nd ed.). New York: The Guilford Press.

Zubaidah Bibi, M. A., Hamidah, Y., \& Wahizah, W. (2019). School Improvement Specialist Coaches Plus (SISC+) Teacher Coaching in Malaysia: Examining the Studies. International Journal of $\begin{array}{llll}\text { Contemporary } \quad \text { Applied } & \text { Researches, } & \text { 125-136. }\end{array}$ https://doi.org/10.1017/CBO9781107415324.004

Zubaidah Bibi, M. A., Yamat, H., \& Wahiza, W. (2020). Understanding Teachers' Anxiety towards the Coaching Programme. International Journal of Academic Research in Business and Social Sciences, 10(7), 869-882. https://doi.org/10.6007/ijarbss/v10-i7/7618 